\title{
A 32 IDENTIDAD Y FRONTERA EN EL MUNDO ATACAMEÑO DEL NORTE DE CHILE: VISIONES CRÍTICAS Y REFLEXIONES ${ }^{1}$
}

\section{Roberto Hernández y Carlos Thomas}

Universidad de Chile. E-mail: rhernan@ctcinternet.cl; rhernan65@yahoo.es

\begin{abstract}
Resumen
Las comunidades indígenas atacameñas del norte de Chile, ubicadas en una región de frontera con Argentina, han tenido un interesante proceso de construcción de nuevas identidades como respuesta a los fenómenos de la modernización desde la década de los años 50, y posteriormente, ante la globalización, desde la década de los 80 hasta los primeros años del siglo XXI. Estos procesos han sido observados por los autores durante 35 años de trabajo antropológico sobre los cambios socioculturales ocurridos en dichas comunidades indígenas. Los resultados obtenidos permiten exponer una visión crítica y algunas reflexiones sobre la situación actual y las proyecciones a futuro de los atacameños en un mundo global que los ha invadido no solamente por medios de comunicación e información, sino también, por la presencia relevante de diversos agentes sociales públicos y privados, nacionales e internacionales, que han intervenido e intervienen actualmente, sobre sus recursos naturales, sus poblaciones, sus culturas locales y principalmente, sobre sus identidades étnicas. Se analiza la intervención de los antropólogos a partir de las investigaciones arqueológicas del padre Gustave Le Paige, como agentes que pretenden contribuir a la construcción de las identidades atacameñas, el impacto de los movimientos a escala mundial sobre reivindicaciones étnicas desde la década de los 80 con la presencia de ONGs y otros agentes invasores que intentan conducir $u$ orientar sus procesos de resignificación étnica, y los fenómenos de interculturalidad que ha traído la globalización, especialmente, a través de los sistemas educativos. Se plantea finalmente, la necesidad de que los atacameños sean los conductores de los procesos de rescate y reconstrucción de sus identidades culturales en función del control de su futuro desarrollo en un mundo globalizado.
\end{abstract}

\section{Palabras claves}

Identidad atacameña, investigaciones antropológicas, movimientos étnicos, interculturalidad y educación intercultural.

\begin{abstract}
The native atacameñas communities in the north of Chile, placed in the border region with Argentina, have had a very interesting process of new identities construction which cause is the modernation phenomena since the 50 decade and after that, the globalization since 80 decade and first years of the XXI century. These processes were watched by this authors in 35 years of anthropological work in the socialcultural changes that had happened in these native communities. The results make possible to expound a critical vision and some thoughts about the situation right now and the future projections of the atacameños in a global world
\end{abstract}

\footnotetext{
${ }^{1}$ Ponencia presentada en el Primer Congreso Latinoamericano de Antropología, Rosario, Argentina, julio, 2005
} 
that it has poured out not only by the media but also by the important presence of a number of social agents publics and privates, national or international, that they had took part or are taking part in subjects like natural resources, villages, local culture and specially in their ethnic identities. It is analyzed the anthropologist intervention, since father Gustave Le Paige archaeological studies, like agents that want to contribute in the construction of the atacameña identity, the impact of the global ethnical vindicate movements since the 80 decade helped by ONG and other invader agents that try to lead or advise their remeaning ethnical process and the intercultural process that has came with the globalization, specially thru the educational system. Finally it is showed the necessity that the atacameños take over the recovery and reconstruction of their cultural identities processes controlling their future development in the global world.

\section{Key words}

Atacameña identity, Anthropologic investigations, Ethnic movements, Interculturalidad and intercultural education

\section{Introducción}

L as comunidades indígenas atacameñas del norte de Chile, ubicadas en una región de frontera con Argentina, han tenido un interesante proceso de construcción de nuevas identidades como respuesta a los fenómenos de la modernización desde la década de los años 50 y posteriormente, ante la globalización y sus agentes externos e internos, que llegan en la década de los años 80, y cuya acción se extiende hasta la primera década del siglo XXI. Estos procesos han sido estudiados por los autores durante 35 años de investigaciones sobre los cambios socioculturales ocurridos en dichas comunidades indígenas. Los resultados obtenidos permiten actualmente exponer algunas visiones críticas y reflexiones sobre la situación presente y las proyecciones a futuro de los atacameños ante un mundo global que los ha invadido no solamente por medios de comunicación e información, sino también, por la presencia relevante de diversos agentes sociales públicos y privados, nacionales e internacionales, que han intervenido e intervienen actualmente, sobre sus recursos naturales, sus poblaciones, sus culturas locales y principalmente, sobre sus identidades como grupos étnicos. Cuando se inician los trabajos antropológicos de los autores de este artículo a principios de la década de los años 70 , los habitantes de las diversas comunidades hoy llamadas "atacameñas" se identificaban con su comunidad de orígen. "Yo soy de Caspana", o de Socaire, o de San Pedro de Atacama. En esos tiempos no se identificaban con una denominación de "atacameños". Pero en la década de los años 90 ya se hablaba de "los pueblos atacameños", y sus propios habitantes se reconocían como miembros de una etnia, de una cultura, de una historia y de un territorio común. ¿Cuáles son los procesos que han producido este cambio fundamental? ¿Cuáles son los agentes sociales que han intervenido para cambiar sus identidades? ¿Cuáles son los nuevos fundamentos que han permitido la construcción de nuevas identidades con un fuerte componente étnico? ¿Cuáles son los procesos internos de estas comunidades indígenas que les han permitido lograr la configuración de una identidad atacameña, común para todas las comunidades, superando las identidades locales? Estas son algunas interrogantes principales que como antropólogos nos hacemos actualmente, y ante lo cual nos preguntamos con mucha pertinencia: ¿Cuál es entonces el rol de los antropólogos ante los procesos endógenos que estamos presenciando en el interior de las

(c) Roberto Hernández y Carlos Thomas. Publicado en AIBR. Revista de Antropología Iberoamericana, Ed. Electrónica 
comunidades atacameñas, en la búsqueda de una identidad común que constituya una respuesta adaptativa, capaz de permitir la coexistencia con otras culturas en un mundo globalizado? Para intentar responder a estas interrogantes, nos proponemos en este artículo, analizar primeramente, la intervención de los antropólogos a partir de las investigaciones arqueológicas del padre Gustavo Le Paige, como agentes que pretenden contribuir a la construcción de las identidades atacameñas, al entregar conocimientos sobre esta cultura del desierto, que tiene 10.000 años de antigüedad. Luego, el impacto de los movimientos a escala mundial sobre reivindicaciones étnicas desde la década de los 80, con la presencia de agentes sociales como es el caso de las ONGs y otros agentes invasores que intentan conducir u orientar sus procesos de resignificación étnica, con sus implicancias sociopolíticas; y por último, los fenómenos de interculturalidad que se han multiplicado y se han hecho más complejos con la globalización, especialmente por el impacto de los sistemas educativos que no se renuevan ni se adaptan a las nuevas condiciones socioculturales imperantes. Este artículo plantea como conclusión y propuesta para esta primera década del siglo XXI, la necesidad de que los atacameños sean los conductores de los procesos de rescate y reconstrucción de sus identidades culturales en función de lograr el control de los proyectos que apuntan a su desarrollo actual y futuro, sustentado en sus bases socioculturales y con sus propios recursos naturales, humanos y culturales, ante un mundo globalizado que intenta imponer las condiciones y el estilo de un desarrollo basado en un modelo y una lógica exógena.

\section{Las investigaciones antropológicas y la identidad atacameña}

La llegada del sacerdote jesuita belga, Gustave Le Paige a San Pedro de Atacama y la fundación del Centro de Estudios Arqueológicos en el año 1955 y posteriormente, el Museo de San Pedro de Atacama, marcan un hito importante en el rol de las investigaciones antropológicas sobre las comunidades atacameñas y su identidad. Este investigador se destaca durante casi 30 años en la zona por los estudios de las culturas prehistóricas del desierto de Atacama y por sus relaciones con los pueblos atacameños actuales, debido a su residencia permanente en la zona durante tres décadas hasta su muerte. En ese lapso de tiempo reconoció la presencia de pueblos del desierto que desarrollaron una cultura que pasó por diversos estados de desarrollo, desde las primeras bandas de cazadores y recolectores hasta los pueblos agricultores, que vivían en aldeas y centros fortificados (pukaras). A pesar de reconocer la influencia de las culturas andinas de Bolivia y del norte argentino por su posición de fronteras naturales, destaca la capacidad de estos pueblos del desierto de Atacama para crear su propia cultura con rasgos diferenciados del resto de las culturas andinas. Su impulso a los estudios prehistóricos en la zona tuvo como un objetivo central el buscar sus vinculaciones con los pueblos atacameños contemporáneos. Para esto, además de trabajar incansablemente durante todos estos años, promovió la visita de ilustres investigadores extranjeros y reuniones de especialistas nacionales y extranjeros para discutir sobre la presencia de estos pueblos del desierto de Atacama y sus expresiones culturales (Universidad del Norte, 1976). La incorporación de atacameños en sus trabajos de campo y el apoyo a actividades sociales de esas comunidades, permitieron la creación de lazos afectivos que sirvieron de base para un trabajo de extensión que

(c) Roberto Hernández y Carlos Thomas. Publicado en AIBR. Revista de Antropología Iberoamericana, Ed. Electrónica 
tenía por objetivo el dar a conocer las raíces prehistóricas del pueblo atacameño actual. Como resultado, gracias a la acción del padre Le Paige, se sentaron las bases para la construcción de una identidad atacameña.

Sin embargo, a la muerte de Le Paige, los investigadores que le sucedieron, no siguieron este camino, ya que se han destacado más por su interés académico en función de generar conocimientos arqueológicos y antropológicos para comunicarlos y discutirlos en eventos científicos y artículos publicados en revistas nacionales e internacionales. Se produce un distanciamiento con respecto a las comunidades atacameñas y una escasa comunicación de sus hallazgos para con ellos. Esto permite discutir y reflexionar sobre la necesidad del rol del antropólogo como un investigador comprometido con los procesos de construcción y reconstrucción de identidades culturales, pero respetando los procesos endógenos que se dan en las comunidades, ya que son ellos quienes deben definir y darle contenidos a sus identidades. Esto es, entender las identidades culturales como construcciones sociales a partir del conocimiento y valor de sus culturas locales, percibidas y reflexionadas por las propias comunidades, y no por los centros de investigación. El compromiso social del investigador es dar a conocer sus hallazgos sobre las culturas locales a las comunidades estudiadas, promover el relevamiento de su patrimonio cultural y natural, ser un facilitador para el análisis y reflexiones sobre el valor y significado de sus culturas, y fomentar la construcción de una identidad atacameña por sus propios actores y no por agentes externos, ajenos a su mundo sociocultural. Lo contrario, traería como consecuencia la construcción de una identidad cultural atacameña en el mundo académico, desligada de los actores sociales, sin una base social, que se pretendería imponer a estas comunidades indígenas. Este último fenómeno lo observamos en algunas experiencias ocurridas en las dos últimas décadas, como consecuencia de procesos reivindicativos a nivel mundial.

\section{Los movimientos étnicos y la identidad atacameña}

Desde la década de los años 80 observamos el surgimiento de movimientos reivindicativos de carácter étnicos a escala mundial, que más allá de la búsqueda de una identidad cultural ante el impacto de la globalización y su imposición de una cultura proveniente del primer mundo, demandan el reconocimiento de los grupos indígenas, su cultura, sus derechos y un territorio, en el marco de un sistema social mayor. Esta dimensión sociopolítica del problema determina un cambio importante en los procesos de búsqueda de una identidad atacameña, a pesar que estas comunidades de la II Región de Chile no han participado tan activamente de los movimientos reivindicativos. La presencia de agentes externos nacionales e internacionales ha jugado un papel relevante para impulsar estos procesos de reivindicación étnica, siendo importante analizar sus efectos sobre una identidad cultural atacameña. Sus orígenes provienen del primer mundo, impulsado por ONGs y otros activistas que fomentan y financian proyectos de intervención foránea en las comunidades indígenas del tercer mundo. A estas acciones se pliegan organizaciones e investigadores de centros académicos nacionales, bajo esquemas de acción que pretenden problematizar e interpretar desde una óptica 
exógena las realidades y problemas endógenos de las comunidades indígenas ante un mundo globalizado. Estas instituciones foráneas ya vienen con un discurso definido, con modelos y metodologías de acción probadas en otras realidades, para aplicar de manera vertical sobre las comunidades indígenas, las que se transforman de alguna manera, en simples observadores o participantes semiactivos de los procesos reivindicativos. Con esto se corre el riesgo de caer en utopías que intentan revivir elementos supuestamente patrimoniales, de un pasado histórico que ya no está vigente. Frente a esto es necesario reflexionar sobre cómo reconocer y potenciar la capacidad de comunidades que puedan pensar y reflexionar sobre su pasado y presente, y que tengan competencia para definir quiénes son y qué es lo que quieren para el futuro. El dilema de estos agentes externos es poder precisar qué es políticamente correcto frente a las realidades socioculturales que intervienen y cómo enfrentar los problemas que las mismas comunidades deben identificar. ¿Simplemente conocer estas realidades y sus problemáticas y transmitirlas a los centros de decisión política? ¿Alentar a estas minorías étnicas para demandar al Estado sobre sus derechos y necesidades? ¿Conducir estos movimientos como activistas? O ¿Ser unos facilitadores de las comunidades para que ellos mismos conduzcan sus procesos reivindicativos? Todas estas interrogantes nos entregan una gama de alternativas que tienen las instituciones y los investigadores individualmente considerados, para su acción en las comunidades indígenas.

En el mundo atacameño han ocurrido estas intervenciones de dichos agentes externos, con sus consecuencias negativas para su autonomía de acción ante los retos que impone la globalización. La importación de modelos de desarrollo, las lógicas culturales ajenas a sus culturas locales, las visiones de mundo externas y los modelos de organización social no pertinentes, han sido experiencias fallidas para los atacameños. A esto se suman, las intervenciones de agentes económicos relacionados principalmente con la minería, que han invadido sus territorios a fin de extraer sus recursos naturales. Un capítulo aparte lo constituye la acción del Estado, por su presencia importante y por las falencias de sus intervenciones a través, principalmente de la CONADI. El año 1993 se dicta una Ley Indígena que reconoce la existencia de minorías étnicas que viven actualmente en el territorio chileno, y posteriormente se crea la Corporación Nacional de Desarrollo Indígena (CONADI), institución encargada de ejecutar una política de apoyo a las demandas de los grupos étnicos en los aspectos económicos, jurídicos, políticos, sociales y culturales. Esto implica, defender los derechos de las minorías indígenas a permanecer y desarrollarse dónde están. Sin embargo, el trato con estas minorías no ha sido igualitario, dando preferencia a los mapuches, la minoría indígena más numerosa y más activa en relación a sus planteamientos y acciones reivindicativas. Es lo que algunos especialistas hablan de la "mapuchenización" de la cuestión indígena. La CONADI ha visto entrabada su acción por ser permeable a los intereses políticos y cuotas de poder entre grupos de gobernantes, ajenos a las necesidades y demandas de los grupos étnicos. Esto ha creado desconfianza e insatisfacción con respecto a lo esperado de esta institución oficial. En el caso de los atacameños, ha sido notoria la incapacidad del Estado chileno y sus instituciones ocupadas de los asuntos indígenas, para resolver sobre las demandas de reconocimiento de sus territorios ancestrales y del acceso a la administración y control de sus recursos naturales patrimoniales. A su vez, las universidades

(C) Roberto Hernández y Carlos Thomas. Publicado en AIBR. Revista de Antropología Iberoamericana, Ed. Electrónica 
regionales no han sido capaces de asumir un rol más activo para apoyar las demandas de los atacameños, como facilitadores de los conocimientos y capacidades necesarias de sus líderes y comunidades para poder conducir los procesos de su propio desarrollo en un contexto globalizado. Esto se explica por la preeminencia de sus intereses eminentemente académicos que los desvincula de las comunidades atacameñas.

Un caso paradigmático de lo que no debe ser el desarrollo de las comunidades indígenas es el poblado de San Pedro de Atacama, comunidad que ha sido invadida por "afuerinos", provenientes de los grandes centros urbanos, desplazando a los "lugareños" y apropiándose de sus patrimonios culturales y naturales para sus propios objetivos económicos. Ello se ha traducido en el desarrollo de un turismo rural con sus expresiones étnicas, ecológicas y de aventura. Ante esta situación, los atacameños se han refugiado en sus antiguos "ayllus", como una forma de subsistir frente a la invasión foránea. Entre los líderes atacameños, existe una clara conciencia de que este modelo de desarrollo sólo posibilita la destrucción de la identidad atacameña. Pero a su vez, la experiencia de San Pedro de Atacama, ha hecho reflexionar al liderazgo indígena sobre los peligros que se ciernen sobre todas las comunidades del salar de Atacama y el Alto Loa y sus identidades locales, y también, en relación a la necesidad imperiosa de iniciar un proceso de búsqueda y construcción de una identidad atacameña bajo la conducción de ellos mismos, desplazando a tantos agentes externos que pretenden intervenir, muchas veces, con buenas intenciones, pero con cosmovisiones ajenas a las culturas locales. Pero en el recorrido del camino trazado por los atacameños hacia esa construcción identitaria, se encuentran dificultades producto de los fenómenos de la interculturalidad que han sido potenciados por la Globalización.

\section{Interculturalidad e identidad atacameña}

El debate teórico sobre la interculturalidad abarca una diversidad de problemas complejos y plagados de contradicciones. Se destacan aspectos cómo el rol del lenguaje, la construcción del sujeto, la teoría misma de la identidad, y la concepción de la realidad y del conocimiento ante un mundo globalizado. El tema mismo de la interculturalidad nos da cuenta de los profundos cambios ocurridos en las sociedades post-industriales, potenciando un mayor conocimiento y vinculaciones de las diversas culturas que coexisten en nuestro mundo contemporáneo. Esto releva las diferencias culturales y el reto que constituye el poder aceptar y valorizar la diversidad. Hay una circulación en el espacio del sentido de lo cultural en la individualidad que está de alguna manera impuesto por una sociedad mayor (Hernández et.al., 2004). Pero el problema a resolver es cómo se aborda y se soluciona la necesidad de los diversos pueblos de poder construir sus propias identidades, ante la amenaza de un sistema mundializado que pretende imponer por distintos mecanismos y aliados estratégicos, un proyecto de cultura global que intenta suprimir esa diversidad cultural. Sabemos que las respuestas a esos intentos por parte de las minorías étnicas se han dado con distintos niveles de radicalización. Como un caso extremo, en Chile se destacan los Rapanuí, por sus aspiraciones de constituirse en un estado dentro del Estado chileno, con la correspondiente autonomía política y 
administrativa. Existe un consenso que los elementos comunes de todos los pueblos originarios considerados como base para la construcción de nuevas identidades son: un territorio, una historia común, una cultura y un lenguaje. Hoy el concepto de interculturalidad enfatiza en el contacto, en el diálogo entre culturas, la interacción y la interlocución, la reciprocidad y la confrontación entre identidad y diferencia (Gouvea, 2003). En este concepto está involucrado un diálogo fecundo de culturas que se encuentran, y que se retroalimentan recíprocamente, en un plano horizontal. Como se ve, el problema de la interculturalidad en un mundo actual, se constituye en un elemento fundamental para poder comprender mejor las condiciones en que se desarrollan los procesos de construcción de nuevas identidades de las minorías étnicas como es el caso de los atacameños.

Autores clásicos de la historiografía chilena como Diego Barros Arana, señalan que no hay diferencias culturales entre los diversos pueblos originarios. Esto corresponde a una concepción hegemónica del sistema social mayor imperante en esa época, que pretendía imponer una cultura chilena a todos los habitantes de este país. Pero actualmente, el reconocimiento de las diferencias culturales no es una simple expresión de un concepto sin contenido real, sino que corresponde a una realidad concreta e histórica. Las culturas y las identidades son dinámicas, por lo tanto, cambiantes. Así en el caso de los atacameños, sus identidades fueron cambiando ante las nuevas condiciones sociohistóricas, desde la prehistoria, en el período de Tiawanacu, período Inca, dominio colonial español, dominio del Estado boliviano, dominio del Estado chileno y época actual. No es el objeto de este trabajo analizar todos estos procesos, pero sí tratar de comprender los procesos actuales de construcción de nuevas identidades, como un devenir que hunde sus raíces en una tradición prehistórica e histórica. En este sentido, el interculturalismo pone de relieve la necesidad de definir las identidades culturales de los atacameños, sin poner meros límites de fronteras naturales, como lo pretendió una elite monocultural dominante. Hoy, estas minorías étnicas han aprendido a explotar entidades liberales y conservadoras, y sistemas políticos democráticos, para llegar a imponer cambios y momentos de armisticio, para sacar adelante sus proyectos de identificación identitaria. Las culturas locales actuales deben ser comprendidas en su vertebración con la cultura mayor, sin caer en posiciones utópicas que pretenden buscar las bases de la identidad de las minorías étnicas, en un pasado histórico y elementos culturales no reconocidos como vigentes para las comunidades indígenas en la actualidad. Sobre estos procesos se requiere reflexionar a fin de definir cuál es el camino correcto o pertinente para contribuir a sus procesos identitarios. Determinar las metodologías más adecuadas para lograr estos propósitos. Indagar en el pasado y en el presente sobre sus costumbres y tradiciones que están vigentes, o sea, reconocidas y validadas socialmente por las comunidades indígenas actuales. En definitiva, pesquisar sobre las bases y expresiones actuales de sus identidades. En el caso de los atacameños, llama poderosamente la atención determinadas formas de expresiones religiosas vinculadas con creencias ancestrales, que aún perviven en fiestas tradicionales como la "limpia de canales". El calendario de fiestas de las comunidades atacameñas, constituye una importante manifestación de su identidad que sobrepasa las fronteras físicas, ya que a ellas acuden los miembros de las comunidades residentes fuera del mundo atacameño.

(c) Roberto Hernández y Carlos Thomas. Publicado en AIBR. Revista de Antropología Iberoamericana, Ed. Electrónica 
La educación formal ha sido históricamente un instrumento de imposición de una cultura nacional dominante, con intenciones explícitas de supresión de las culturas locales. Hoy, frente a las controversias provocadas por los fenómenos de la interculturalidad y el reconocimiento de la diversidad cultural, se plantea para los sistemas educativos formales, un nuevo rol: ser facilitadores de los procesos de reconstrucción de las identidades culturales de las minorías indígenas y otras minorías sociales (Gómez, 1999; Hernández y Thomas, 2004). Esto conlleva a discutir y reflexionar sobre cómo enfrentar estas nuevas tareas. Un primer paso necesario a dar es vincularse con las realidades locales, los problemas, aspiraciones y proyectos de vida de las comunidades indígenas. Luego, situarlos en los contextos globales, entregándoles conocimientos de las nuevas realidades que enfrentan. Indagar y relevar sobre sus culturas locales, principalmente, sobre sus cosmovisiones, sistemas valóricos y elementos patrimoniales. Capacitarlos para tener autonomía en la conducción de los procesos identitarios y promover el endodesarrollo. Propiciar el encuentro de culturas diversas que se expresan en los centros educativos, contribuir a superar la discriminación y segregación social, y promover el respeto a la diversidad cultural. En el caso atacameño se trata de apoyar la construcción de un sujeto atacameño, orgulloso de su cultura ligada estrechamente al desierto y poseedor de una identidad capaz de relacionarse horizontalmente con las otras identidades presentes en un mundo globalizado.

\section{Conclusiones}

La comprensión y reflexión sobre los procesos de construcción de una identidad atacameña ante un mundo globalizado están supeditadas por un análisis crítico de tres fenómenos que han intervenido con un rol determinante: $1^{1}$. el desarrollo de las investigaciones antropológicas y el impacto de la generación de conocimientos sobre la cultura atacameña; $2^{\circ}$. los movimientos de reivindicaciones étnicas a nivel mundial que han provocado la organización y el surgimiento de demandas de diversa naturaleza en las comunidades indígenas chilenas; y $3^{\circ}$. los fenómenos de interculturalidad que se expresan con tensiones, en diversos espacios sociales, principalmente en los centros educativos, que potencian la necesidad de rescatar o construir sus identidades.

Se destaca el rol fundamental que puede jugar la educación formal como facilitadora para la construcción identitaria de los atacameños, fomentando el control que deben tener las comunidades indígenas sobre el relevamiento de sus culturas locales y su identidad, ante la invasión de agentes externos que intervienen sobre ellos, pretendiendo ser aquellos, los conductores de estos procesos. Son los atacameños los encargados de reflexionar sobre su propio pueblo y su futuro, definir qué es ser atacameño, porqué han decidido permanecer en estos territorios desérticos, cuáles son las bases fundamentales de su identidad, cuál es el significado y el valor de su historia común, cuáles son sus vínculos con sus antepasados prehistóricos, y finalmente, determinar cuál es su futuro en este mundo global que interviene a través de diversos agentes externos.

(c) Roberto Hernández y Carlos Thomas. Publicado en AIBR. Revista de Antropología Iberoamericana, Ed. Electrónica 


\section{Bibliografía}

Chiodi y Bahamondes (2001). Una escuela, diferentes culturas. CONADI. Santiago de Chile: Lom Ediciones.

Gómez, Domingo (1999). Diseño de un currículum de Educación Intercultural Atacameño (NB2). Instituto de Investigaciones Antropológicas, Universidad de Antofagasta, Chile.

Gouvea, Celia Leticia (2003). Interculturalidade e educacao escolar indígena: um breve histórico. En Cadernos de Educacao Escolar Indígena, Vol. 2, № 1: 173-188. Brasil: UNEMAT.

Hernández et. al. (2004). Evaluación de la eficiencia programática y la pertinencia intercultural del Programa de Educación Intercultural Bilingüe del Ministerio de Educación en Escuelas de la Región Metropolitana. Informe final. Gobierno Regional Metropolitano, Santiago de Chile.

Hernández y Thomas (2004). Cultura, Desarrollo y Educación en las comunidades atacameñas de la II Región de Chile. En Revista Enfoques Educacionales, Vol. 6, № 1: 93-114. Departamento de Educación, Facultad de Ciencias Sociales, Universidad de Chile.

Universidad del Norte (1976). Homenaje al Dr. Gustavo Le Paige, SJ. San Pedro de Atacama, Chile. 